\title{
The role of short message services (SMS) on childhood immunization in a tertiary health facility in Nasarawa State
}

\author{
Surajudeen Oyeleke Bello, ${ }^{1}$ Ruben Jerry Chuma, ${ }^{1}$ Taofeek Oluwaseun Ogunkunle, ${ }^{1}$ \\ Olayinka Rasheed Ibrahim, ${ }^{2}$ Oyetundun Fausat Afolabi, ${ }^{3}$ Hamdalla Issa, ${ }^{4}$ \\ Immaculata Chinwe Anderson, ${ }^{1}$ Chidi Michael Anazodo ${ }^{5}$
}

${ }^{1}$ Department of Paediatrics, DalhatuAraf Specialist HospitalLafia, Nasarawa State; ${ }^{2}$ Department of Paediatrics, Federal Medical Centre Katsina, Katsina State; ${ }^{3}$ Department of Paediatrics, Bwari General Hospital, Federal Capital Development Authority Abuja; ${ }^{4}$ Department of Paediatrics, General Hospital Ilorin, Kwara State; ${ }^{5}$ Department of Public Health, DalhatuAraf Specialist Hospital, LafiaNasarawa State

\author{
Correspondence: Surajudeen Oyeleke Bello, Department of Paediatrics, \\ DalhatuAraf Specialist Hospital, LafiaNasarawa State \\ Tel.: +2347064641540 \\ E-mail: surajudeenbello4@gmail.com
}

Key words: Children; Immunization; Role; SMS.

Contributions: BSO: conception, design, data analysis and interpretation; drafting of manuscript and review; final approval on manuscript; agreement on its contents. CRJ: data analysis and interpretation; drafting of manuscript; final approval on manuscript; agreement on its contents. OTO: conception and data interpretation; drafting and review of manuscript; final approval on manuscript; agreement on its contents. IOR: design and analysis; drafting of manuscript; approval on manuscript; agreement on its contents. AOF: design and interpretation; drafting of manuscript review; final approval on manuscript; agreement on its contents. IH: analysis and interpretation; drafting of manuscript and review; final approval on manuscript; agreement on its contents. AIC: design and analysis; drafting of manuscript; final approval on manuscript; agreement on its contents. ACM: design and analysis; drafting of manuscript and review; final approval on manuscript; agreement on its contents.

Conflict of interest: The authors declare no conflict of interest

Acknowledgement: All parents who participated in the study I hereby acknowledged.

Funding: None.

Ethical approval and consent to participate: Ethical approval was obtained from the Hospital Research Ethics Committee of the Dalhatu Araf Specialist Hospital Lafia Nasarawa State.A written informed consent was obtained before enrolment.

Consent for publication: All responders agreed and consented to this publication.

Availability of data and materials: All data generated or analyzed in this study are presented in this published article.

Received for publication: 3 June 2020.

Revision received: 5 August 2020.

Accepted for publication: 12 August 2020.

This work is licensed under a Creative Commons Attribution NonCommercial 4.0 License (CC BY-NC 4.0).

${ }^{C}$ Copyright: the Author(s),2020

Licensee PAGEPress, Italy

Annals of Clinical and Biomedical Research 2020; 1:84

doi:10.4081/acbr.2020.84

\begin{abstract}
Background: Immunization has remained the most cost effective strategy of reducing global childhood deaths and disabilities. The diseases and illnesses targeted by the process of vaccination to achieving immunization are termed Vaccine Preventable Diseases (VPD). Vaccine preventable diseases constitute a major burden to under-five morbidity and mortality in developing countries like Nigeria.This key strategy is being hindered by factors such as forgetfulness and accessibility challenges among others. This study seeks to evaluate the place of using remindersin the form ofShort Message Services (SMS) and or phone calls in improving health seeking behavior through immunization.

Materials and Methods: A questionnaire based cross sectionalstudies was carried out between $1^{\text {st }}$ of July to the $31^{\text {st }}$ of December 2019 on the Children Medical Wards of the DalhatuAraf Specialist Hospital. The role of SMS and preference of care-givers between SMS and phone calls on immunization activities was determined. Data analyses were done using the Statistical Package for Social Sciences (SPSS) version 20.

Results: The mean age of mothers in this study is $27.58 \pm 5.82$ years, as most mothers (58.5\%) were aged between 21-30 years. Almost all of the responders in this study were married except two (one single mother and a widow respectively). More than $90 \%$ had a phone. In spite of this, one fifth of the mothers agreed to have missed immunization at some point. Most $(82.2 \%)$ of the responders believed using SMS as a reminder will reduce the rate of missed immunization. Loss of immunization cards and forgetfulness were the leading reasons for missed immunization in this study.

Conclusions: Most mothers in the present study believed SMS will reduce the rate of missed immunization and preferred it to phone calls.
\end{abstract}

\footnotetext{
Introduction

Immunization has remained the most cost effective strategy of reducing global childhood deaths and disabilities. ${ }^{1}$ Vaccine preventable diseases constitute a major burden to under five morbidity and mortality in developing countries like Nigeria. ${ }^{2,3}$ Most of these diseases are no longer of public health importance as a result of immunization activities. ${ }^{4}$ This key strategy is being hindered by factors such as forgetfulness, acceptability and accessibility challenges among others. ${ }^{5}$ Tackling forgetfulness can be done through sending immunization reminders in the form of Short Message Services (SMS) and or making phone calls. ${ }^{6}$ Reminders for immunization has been shown to improve health seeking behavior con-
} 
cerning routine and even supplementary immunization activities. ${ }^{7}$ Kazi et al. ${ }^{8}$ in Karachi Pakistan had reported that SMS is effective and efficient in ensuring on time immunization. The use of mobile phone has increased among Nigerian women considerably in the last few years due to reduce cost of phones, reduce charges by the telecommunication service operators and improved awareness as well as purchasing power. ${ }^{9}$ Ekhaguere and colleagues ${ }^{10}$ in a randomized study in Ondo State, reported a significant improvement in immunization completion rate and timeliness among those that received either phone call or SMS compared with the controls. A study in South Western Nigeria by Adebayo and her colleagues ${ }^{11}$ on the reasons for delayed on incomplete immunization ranges from too busy schedule, postponement and lack of motivation by the mother, all of which can be addressed with either SMS or phone call. There is paucity of data in Northern Nigeria on the role of this important tool (SMS) in assessing it impact on the most cost effective health intervention (immunization). This study therefore set out to find out the role of SMS on immunization and to determine mothers' preference between SMS and phone call as reminders for immunization.

\section{Rationale for the study}

The few earlier studies cited were either outside Nigeria or completely in the Southern part of the country. We therefore conducted this study among parents/caregivers of children admitted and recovering from various ailments at the Children medical ward of a tertiary health facility in North Central Nigeria to determine the effect of SMS on immunization. This will provide basic information that will guide policy makers on planning for both the routine and supplementary immunization activities, influence health care workers in the field of immunization. It will also address the knowledge gap. The study will answer the following research questions:i) What is the role of SMS on routine/supplementary immunization? ii) What is the preference of caregivers between SMS and phone call?

\section{Aim and objectives}

Aim

To determine the role of SMS on immunization activities

\section{Specific objectives}

i) To determine the role of SMS on immunization activities; ii) To evaluate the preference of caregivers between SMS and phone call.

\section{Materials and Methods}

\section{Study design}

This was a questionnaire based cross-sectional study.

\section{Study site}

The study was conducted at the Children Medical Ward of DalhatuAraf Specialist Hospital (DASH) Lafia in Nasarawa State.

Nasarawa State has boundaries with the FCT Abuja in the West, Kaduna State in the North, Plateau and Taraba States in the East, Benue and Kogi States in the South. It has a landmass of $27,117 \mathrm{~km}^{2}\left(10,470 \mathrm{~m}^{2}\right)$. Its total population according to the 2006 National Population Census was 1,869,377. Nasarawa State's mainstay of economy is Agriculture and has some mineral resources such as Salt, it is known as the State of solid minerals. The State has diverse ethnicity with some of the major tribes being Alago, Eggon, Mada, Kanuri, Hausa-Fulani, Koro (Migili), Gwandara, Afo, Ebira etc.

\section{Study population}

The study was done among all mothers and caregivers of children on admission and recuperating from various ailments at the Children Medical Ward in DASH Lafia Nasarawa State Nigeria from $1^{\text {st }}$ July 2019 to the 31 December 2019.

\section{Sample size}

All the mothers and caregivers of children on admission were approached for participation.

\section{Sampling technique}

A convenience sampling technique was used.

\section{Procedure for recruitment}

Parents/caregivers of children admitted within the study period were approached for participation. Detailed information about the study, its benefit, risk factors and its confidentiality were explained. They were also told that participation for the study is voluntary and they can withdraw anytime they feel like doing so, non participation won't affect the care for the child, and all information will be treated with utmost confidentiality. A written informed consent was obtained before enrolment. Those enrolled have questionnaire administered by the researchers or the trained research assistants.

\section{Ethical consideration}

Ethics approval was obtained from the Hospital Research Ethics Committee of the Dalhatu Araf Specialist Hospital LafiaNasarawa State.

\section{Data analysis}

The data was coded and enter into an excel spreadsheet before transferring to a Statistical Package for Social Sciences (SPSS) version 20. Categorical variables were presented using frequency and percentages. Association between two categorical variables was determined using chi square. Results were arranged in tables and chart. The $p$ value was considered significant at $p<0.05$.

\section{Results}

\section{Demographic factors of the study population}

A total of a hundred and thirty five mothers were enrolled in this study. The mean age of mothers was $27.58 \pm 5.82$ years, as most mothers (58.5\%) were aged between 21-30 years. Almost all the responders were married except two (one single mother and a widow respectively).About three quarters of the married responders were of the monogamous family (Table 1).

Table 1. Demographic factors of the study population.

\begin{tabular}{lcc}
\hline Variables & Frequencies & Percentages \\
Mothers age range (years) & & \\
$15-20$ & 18 & 13.3 \\
$21-30$ & 79 & 58.5 \\
$31-40$ & 36 & 26.7 \\
$41-50$ & 2 & 1.5 \\
Marital status & & \\
$\quad$ Married & 133 & 98.4 \\
Single & 1 & 0.8 \\
$\quad$ Widow & 1 & 0.8 \\
\hline Marriage type & & \\
Monogamous & 105 & 77.8 \\
Polygamous & 30 & 22.2 \\
\hline
\end{tabular}




\section{Distribution of ethnic groups and family size}

The major ethnic groups based on this study population are Hausa,Eggon, Alago, Fulani and Kambari respectively. Most mothers have two or less children (Table 2).

\section{Effects of having formal education and a mobile device on the rate of reduction and the rate of missed immu- nization}

Less than one sixth of the study population had no formal education, while more than $90 \%$ had a phone. Possession of a mobile phone as well as the care-givers having a formal education are statistically significant reduction in the rate of missed immunization. However, having formal education does not have a significant effect on the rate of missed immunization. Most (82.2\%) of the responders believed using SMS as a reminder will reduce the rate of missed immunization although this was not statistically significant $(\mathrm{p}=0.085)$ Table 3 .

\section{Missed immunization: prevalence and contributing factors}

The prevalence of missed immunization is $17.8 \%$ and it is as a result of caregivers forgetfulness, unavailability of caregivers and misplaced immunization card in $18.5 \%, 14.8 \%$ and $29.6 \%$ of respondents respectively (Table 4 ).

Most of the respondents $(\mathrm{n}=111,82.2 \%)$ preferred SMS as a form of reminder, $21(15.6 \%)$ preferred phone call alone while the remaining three $(2.2 \%)$ the combination of both SMS and phone call (Figure 1).

\section{Discussion}

Immunization is perhaps the most cost effective intervention strategy to curtail the burden of most childhood infectious diseases. ${ }^{1}$ The prevalence of missed immunization in this study is $17.8 \%$ and is consistent with other hospital based point prevalence studies. ${ }^{12,13}$ This may however, not be a true reflection of status of immunization in the entire population. Indeed, a secondary data

\section{Reminder preference of respondents}

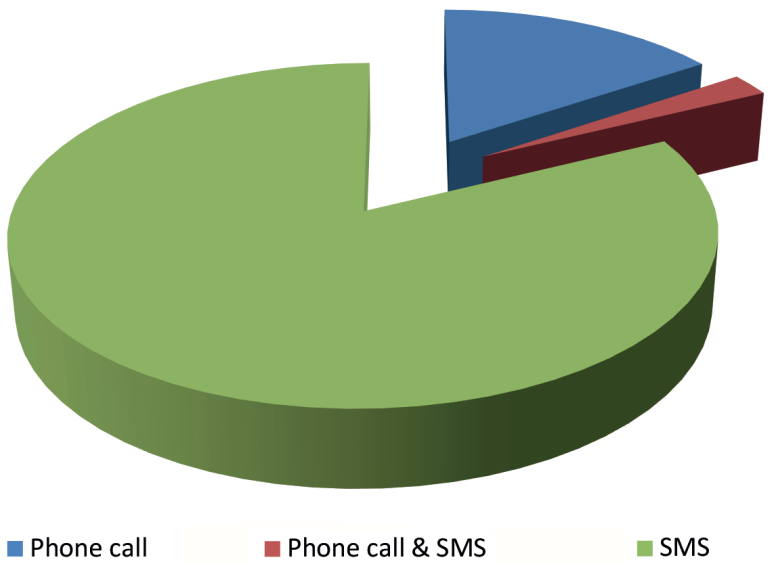

Figure 1. Reminder preference of respondents. analysis of the Nigeria Demographic and Health Survey involving about six thousand children aged 12-23 months, nested in about 900 communities across the 36 states revealed that $76.3 \%$ of the population have not been completely immunized. ${ }^{14}$ This brings to the fore the burden of missed opportunity for immunization and the need for a pragmatic action to stem its tide.

The protective efficacy is however hinged on the completion of the scheduled vaccination and this could be affected by caregivers' forgetfulness. In this study about $30 \%$ and $20 \%$ of the participants cited loss of immunization card and forgetfulness respec-

Table 2. Distribution of ethnic groups and family size.

\begin{tabular}{lcc} 
Variables & Prequencies & Percentages \\
Ethnicity & & \\
Hausa & 28 & 20.7 \\
Eggon & 17 & 12.6 \\
Alago & 17 & 12.6 \\
Fulani & 12 & 8.9 \\
Kambari & 12 & 8.9 \\
Yoruba & 5 & 3.7 \\
Igbo & 5 & 3.7 \\
Koro & 5 & 3.7 \\
Mada & 4 & 3.0 \\
Gwandara & 3 & 2.2 \\
Nupe & 2 & 1.5 \\
Afo & 2 & 1.5 \\
Others & 23 & 17.0 \\
Number of children & & \\
1-2 & 75 & 55.6 \\
$3-4$ & 39 & 28.9 \\
$\geq 5$ & 21 & 15.5 \\
\hline
\end{tabular}

Table 3. Effects of having formal education and a mobile device on the rate of reduction and the rate of missed immunization.

\begin{tabular}{lcccc} 
Variables & \multicolumn{5}{c}{ Missed immunization } \\
& Yes n (\%) & No n (\%) & $\chi^{2}$ & p-value \\
Have formal education? & & & & \\
$\quad$ Yes & $21(17.9)$ & $96(82.1)$ & 8.830 & 0.039 \\
$\quad$ No & $3(16.7)$ & $15(83.3)$ & & \\
Have mobile device & & & & \\
$\quad$ Yes & $20(16.1)$ & $104(83.9)$ & 33.60 & 0.001 \\
No & $4(36.4)$ & $7(63.6)$ & & \\
\hline
\end{tabular}

Table 4. Contributors to missing immunization.

$\begin{array}{lcc}\text { Variables } & \text { Frequencies } & \text { Percentages } \\ \text { Missed immunization (N=135) } & & \\ \text { Yes } & 24 & 17.8 \\ \quad \text { No } & 111 & 82.2 \\ \text { Reasons } & & \\ \text { Loss of immunization card } & 40 & 29.6 \\ \text { Forgot immunization day } & 25 & 18.5 \\ \text { Travelled } & 20 & 14.8 \\ \text { Unpleasant experience } & 10 & 7.4 \\ \text { Conflict } & 5 & 3.7 \\ \text { Vaccine stock out } & 5 & 3.7 \\ \text { Father's refusal } & 5 & 3.7 \\ \text { Child was sick } & 5 & 3.7 \\ \text { Mother's ill health } & 5 & 3.7 \\ \text { Lack of transport fare } & 4 & 3.0 \\ \text { Others } & 11 & 8.2\end{array}$


tively as the reason for missing immunization clinic visits and this is consistent with the earlier reports, suggesting that it is a major problem. ${ }^{15}$ Forgetfulness is human but there is a strong evidence that simple reminders about timing of appointments are effective at helping forgetful clients keep their appointments. ${ }^{15,16}$

Consistently, over eighty percent of this study population believed that SMS is a viable and effective tool to strengthening immunization by reducing the rate of missed immunization. This is comparable to the $84 \%$ reported by Ekhaguere et al. ${ }^{10}$ in Ondo State in a randomized study. The similarity in socio-demographic characteristics of the recruited subjects may have been responsible for the observed similarity.

According to Oladepo and colleagues however, $90.5 \%$ of their respondents were affirmative of the impact of mobile phone as reminder on the completion of immunization and reducing missed immunization. ${ }^{9}$ This relatively higher rate may be attributed to a larger sample size of heterogenous respondents drawn from immunization clinics across the six geopolitical zones of Nigeria and the use of focused group discussion for data collection.

Only $15.6 \%$ of caregivers in the present study preferred phone call only while majority preferred SMS as a reminder for immunization. This is perhaps because phone calls might be missed but an SMS would remain on the phone for reference and could improve the effectiveness of the reminder. In contrast, a study by Ibraheem et al. ${ }^{1}$ in Ilorin, found close to $50 \%$ of their respondents preferring phone calls alone. Breach of their confidentiality and the concerns over possibility of receiving multiple messages over time as been cited as draw back to the use of SMS reminders and may have been responsible for the phone call preference in their study. ${ }^{16}$ A significant proportion of the responders with formal education had immunization as at when due similar to the report from Ilorin. ${ }^{1}$

It is therefore imperative that mobile phone based reminder programs should take into consideration the preference of end users in the planning and execution of such interventions. Furthermore, possessing a mobile phone was associated with a significantly lower rate of missed immunization underscoring the huge potential of mobile phone in health care service delivery. This is very important as majority ( $>90 \%)$ of respondents in this study had mobile devices and this would be pivotal to planning intervention programs geared towards improving childhood immunization and other child health programs.

\section{Conclusions}

Most of the caregivers wanted to be reminded about their children immunization as they mostly posited that a reminder via their mobile devices will reduce the rate of missed immunization. Additionally, having formal education as well as a mobile phone were associated with a significantly lower rate of missed immunization and this would be critical to planning intervention programs geared towards improving childhood immunization.

\section{References}

1. Ibraheem R, Akintola M, Abdulkadir M, et al. A comparative analysis of mothers preference for specific type of phone derived reminders for routine immunization appointments in Ilorin, Nigeria. J Med Trop 2018;20:42-8.

2. Ibraheem R, Bello A, Adeboye M, et al. Missed Vaccination opportunities at a Secondary Health Facility in Ilorin Nigeria. J Community Med Prim Heal Care 2016;28:31-7.

3. Abdulkarim A, Ibrahim R, Fawi A, et al. Vaccines and immunization: The past, present and future in Nigeria. Niger $\mathrm{J}$ Paediatr 2011;38:186-94.

4. Tagbo BN, Eke CB, Omotowo BI, et al. Vaccination Coverage and Its Determinants in Children Aged 11-23 Months in an Urban District of Nigeria. World J Vaccines 2014;4:175-83.

5. Oku A, Oyo-Ita A, Glenton C, et al. Factors affecting the implementation of childhood vaccination communication strategies in Nigeria: a qualitative study. BMC Public Health2017;17:1-12.

6. Fajola AO, Ekanem EE, Ande BA, et al. Immunization Completion Rates in a Cottage Hospital in the Niger Delta Area of Nigeria. Ann Med Health Sci Res 2018;8:51-3.

7. Manakongtreecheep K. SMS-reminder for vaccination in Africa: research from published, unpublished and grey literature. Pan Afr Med J 2017;27:23.

8. Kazi AM, Murtaza A, Kazi AN, et al. Effect of Mobile Phone Text Messages Reminders on Uptake of Routine Immunization among Children in Pakistan-Study Protocol for a Randomized Clinical Trial. J Vaccines Vaccin;7. doi: 10.4172/21577560.1000333.

9. Oladepo O, Dipeolu IO, Oladunni O. Nigerian rural mothers' knowledge of routine childhood immunizations and attitudes about use of reminder text messages for promoting timely completion. J Public Health Policy 2019;40:462-80.

10. Ekhaguere OA, Oluwafemi RO, Badejoko B, et al. Automated phone call and text reminders for childhood immunisations (PRIMM): A randomised controlled trial in Nigeria. BMJ Glob Heal 2019;4:1-9.

11. Adebayo BE, Oladokun RE, Akinbami FO. Immunization coverage in a rural community in Southwestern Nigeria. J Vaccines Vaccin; 3. doi: 10.4172/2157-7560.1000143.

12. Nnewi H. The Prevalence of Missed Opportunities for Immunization among Children Utilizing Immunization Services in Nnamdi Azikiwe University Teaching The Prevalence of Missed Opportunities for Immunization among Children Utilizing Immunization Services In NNAMDI A. J Biol Agric Res 2012;2:112-22.

13. Wemakor A, Helegbe GK, Abdul-mumin A, et al. Prevalence and factors associated with incomplete immunization of children (12-23 months) in Kwabre East District, Ashanti Region, Ghana. Arch Public Heal 2018;76:67-75.

14. Adedokun ST, Uthman OA, Adekanmbi VT, et al. Incomplete childhood immunization in Nigeria: a multilevel analysis of individual and contextual factors. BMC Public Health 2017; 17:236-46.

15. Schwebel FJ, Larimer ME. Using text message reminders in health care services: A narrative literature review. Internet Interv 2018;13:82-104.

16. Mclean S, Gee M, Booth A, et al. Health services and delivery research. Natl Inst Heal Res 2014;2:1-216. 